\title{
Eine neue Calopepla-Art
}

\author{
beschrieben von
}

C. $\boldsymbol{S} \boldsymbol{t}$ å $\boldsymbol{l}$ in Stockholm.

\section{Calopepla Bohemaniana Stål.}

Viridi-aenea, nitida, subtus cyaneo-induta; thorace impressionibus pluribus instructo; elytris seriatim excavato-punctatis. -

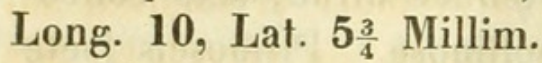

Patria: Laos. (Mus. Reg. Holm.)

Subovata, modice convexa. Antennae nigrae, basin versus leviter aenescente-nitidis. Caput laeve, pone oculos impressum. Thorax impunctatus, antrorsum subrotundato - angustatus, apice capite haud latior, marginibus antico sinuato et lateralibus reflexis, sulco medio longitudinali, prope basin abbreviato, posterius latiore et profundiore, nec non utrimque impressionibus quinque vel sex instructus. Elytra lateribus longius ante medium leviter sinuatis, medio subampliatis, impressionibus numerosis, in series longitudinales, dorso regulares, latera versus confusas, instructa. Prostethium margine antico infra os leviter rotundato-prominente; prosterno postice subtruncato, angulis posticis rotundatis. Mesosternum antice minus pro. funde impressum. 


\section{$2 \mathrm{BHL}$ Biodiversity Heritage Library}

Stål, Carl. 1863. "Eine neue CalopeplaロArt.'Berliner entomologische Zeitschrift / herausgegeben von dem Entomologischen Vereine in Berlin 7(1प2),56-56. https://doi.org/10.1002/mmnd.18630070105.

View This Item Online: https://www.biodiversitylibrary.org/item/36389

DOI: https://doi.org/10.1002/mmnd.18630070105

Permalink: https://www.biodiversitylibrary.org/partpdf/209964

\section{Holding Institution}

Smithsonian Libraries

\section{Sponsored by}

Smithsonian

\section{Copyright \& Reuse}

Copyright Status: Public domain. The BHL considers that this work is no longer under copyright protection.

This document was created from content at the Biodiversity Heritage Library, the world's largest open access digital library for biodiversity literature and archives. Visit BHL at https://www.biodiversitylibrary.org. 